\title{
Long-Period Building Response to Earthquakes in the San Francisco Bay Area
}

\author{
by Anna H. Olsen, Brad T. Aagaard, and Thomas H. Heaton
}

\begin{abstract}
This article reports a study of modeled, long-period building responses to ground-motion simulations of earthquakes in the San Francisco Bay Area. The earthquakes include the 1989 magnitude 6.9 Loma Prieta earthquake, a magnitude 7.8 simulation of the 1906 San Francisco earthquake, and two hypothetical magnitude 7.8 northern San Andreas fault earthquakes with hypocenters north and south of San Francisco. We use the simulated ground motions to excite nonlinear models of 20-story, steel, welded moment-resisting frame (MRF) buildings. We consider MRF buildings designed with two different strengths and modeled with either ductile or brittle welds. Using peak interstory drift ratio (IDR) as a performance measure, the stiffer, higher strength building models outperform the equivalent more flexible, lower strength designs. The hypothetical magnitude 7.8 earthquake with hypocenter north of San Francisco produces the most severe ground motions. In this simulation, the responses of the more flexible, lower strength building model with brittle welds exceed an IDR of $2.5 \%$ (that is, threaten life safety) on 54\% of the urban area, compared to $4.6 \%$ of the urban area for the stiffer, higher strength building with ductile welds. We also use the simulated ground motions to predict the maximum isolator displacement of base-isolated buildings with linear, single-degree-of-freedom (SDOF) models. For two existing 3 -sec isolator systems near San Francisco, the design maximum displacement is $0.5 \mathrm{~m}$, and our simulations predict isolator displacements for this type of system in excess of $0.5 \mathrm{~m}$ in many urban areas. This article demonstrates that a large, 1906-like earthquake could cause significant damage to long-period buildings in the San Francisco Bay Area.
\end{abstract}

\section{Introduction}

The northern San Andreas fault produced the devastating 1906 San Francisco earthquake. The same fault may produce a similar earthquake in the future, and the consequences of a similar earthquake in a modern, urban area are uncertain. The city of San Francisco and surrounding communities are significantly different than they were 100 years ago. Specifically, urban areas now include long-period buildings that have been built only in the last several decades. To better understand the possible performance of these long-period buildings in San Francisco's next great earthquake, we study the response of two examples of long-period buildings: 20story, steel, welded moment-resisting frame (MRF) and baseisolated buildings.

Experience provides few examples of steel-frame responses in great (magnitude $>7.5$ ) earthquakes. Contemporary and modern reconnaissance reports of the 1906 San Francisco earthquake conclude that the steel frames existing in 1906 performed well in the severe ground motions (Soulé, 1907; Tobriner, 2006). However, the steel frames in 1906 were markedly different than modern frames. The tallest building in 1906 San Francisco was the 18-story braced-frame Call Building, and Soulé (1907) notes only nine steel-frame buildings between nine and 12 stories; modern steel-frame buildings are often much taller. Also, modern structural engineers can choose longer-period, MRFs rather than the shorter-period, braced frames, which were state-ofthe-art 100 yr ago. (See Hamburger and Nazir (2003) for a brief discussion of historic and modern steel frames.) Because modern steel frames may be taller and have modern designs, it is difficult to infer the performance of modern steel frames based on the reported response of 1906 buildings. Whereas one great earthquake tested steel frames designed a century ago, there are several examples of modern steel-frame responses in smaller earthquakes (Hamburger and Nazir 2003). In particular, tall steel-frame buildings showed either repairable or no damage following both the 1994 magnitude 6.7 Northridge and 1995 magnitude 6.9 Kobe earthquakes. However, in the Northridge earthquake, the largest recorded ground displacement near a building was $0.31 \mathrm{~m}$ near the Olive View Hospital. Somerville et al. 
(1995) provide recorded and simulated ground motions at seven building sites; none of these ground motions exceeds $0.3 \mathrm{~m}$. Dynamic ground displacements beneath tall steel frames were less than $0.5 \mathrm{~m}$ in the Kobe earthquake (Building Research Institute, 1996). Furthermore, investigations of modern, steel MRF buildings after the Northridge earthquake demonstrated that many welds in existing moment-resisting joints are brittle (Gilani, 1997). The SAC Steel Project reports document this widespread problem (e.g., Krawinkler, 2000; Roeder, 2000). In this study, we explore the response of MRF buildings with either ductile or brittle welds to strong ground motions with large displacements.

To predict the response of MRF buildings in large and great earthquakes, many research engineers employ numerical models. Luco and Cornell (2000) studied the effect of beam-to-column connection failure on the seismic response of 3-, 9-, and 20-story building models developed by the SAC Steel Project. The authors found that some of their largest ground motions induced interstory drifts in excess of $10 \%$ or caused collapse in the 20 -story building models with the brittle connections they studied. However, the authors did not include internal gravity frames or shear connections in this study, but they found in a separate study that including these features typically reduced large drifts like these responses. Gupta and Krawinkler (2000) used the same SAC building models with no deterioration mechanisms to predict the seismic response at several seismic hazard levels. In some of the ground motions that represent the hazard level of $2 \%$ exceedance in $50 \mathrm{yr}$, the authors noted large drift demands in the 20-story building model designed for the Los Angeles area. They conclude that "the potential for unacceptable performance is not negligible." Lee and Foutch (2006) designed several alternatives to the SAC building models with various strengths. From a nonlinear time history analysis, the authors found that some 20-story models exceeded their interstory drift capacities, including models with higher strengths. Krishnan et al. (2006) studied the response of a common type of building in the Los Angeles area to simulated ground motions from hypothetical magnitude 7.9 ruptures on the southern San Andreas fault. They used a fully three-dimensional building model to compare the responses of 18-story steel MRF buildings designed to the 1982 and 1997 Uniform Building Codes (UBCs). In the simulations, the MRF models showed large drifts, which would threaten life safety in many areas of Los Angeles. The present study augments previous work by applying thousands of simulated, large ground motions to different 20-story building models and by evaluating the building model responses on a regional level near San Francisco.

Base-isloated buildings are a relatively new type of long-period structure, characterized by a purposely built flexible zone in the foundation that supports a superstructure. By design, the natural frequencies of the superstructure are high compared to the effective frequency of the isolation system. Base isolation can significantly reduce highfrequency vibrations of a building because the isolation level does not transfer high-frequency motions to the superstructure. The seismic forces in a building's superstructure are significantly smaller for a base-isolated building compared to an identical building without isolators. However, all isolation systems have a limited range of motion. Depending on the individual system, base-isolated buildings may experience impacts between foundation walls and the superstructure (Heaton et al., 1995). Base-isolation systems performed well during the 1994 Northridge and 1995 Kobe earthquakes (Kelly, 2004) although no base-isolated buildings were in the near-source areas for these earthquakes. Furthermore, these earthquakes produced much smaller ground displacements than those produced in the 1906 magnitude 7.8 San Francisco earthquake. One goal of this study is to estimate isolator displacements that might occur in a large San Andreas fault event like the 1906 San Francisco earthquake. Detailed models of isolation systems would provide the best predictions of isolator behavior, but we do not presently have such models. Instead, we use an equivalentlinear approximation of the isolator system to estimate the isolator displacements in our considered earthquakes.

The 2006 international building code (IBC) requires a dynamic analysis to design base-isolation systems in the San Francisco Bay Area. The designer must perform response spectrum and response history analyses to determine the design and maximum displacements of the isolators, among other design parameters (International Code Council, 2006). The code also specifies that these displacements must not fall below minimum values. Thus, the model response to ground motions may control the design, and the choice of motions may affect the design. If a design engineer uses ground motions larger than those required by the building code, then he or she will call for a system with a larger isolator displacement capacity than an engineer who uses smaller motions. There has been active discussion on the use of near-source ground motions-characterized by a large displacement pulse-for design (e.g., Hall, 1999; Kelly, 1999). Jangid and Kelly (2001) stated that base-isolation systems should be designed primarily to minimize damage to contents (measured by superstructure acceleration) in moderate earthquakes and secondarily to minimize isolator displacement in large pulse-type ground motions. The authors showed the existence of an optimum isolator damping that minimizes superstructure accelerations. This optimum damping does not minimize isolator displacement because isolator displacement monotonically decreases with increasing damping. Ryan and Chopra (2004b) compared the results of a nonlinear analysis of base-isolation systems to the equivalent-linear procedure of the 2000 IBC used to determine the design displacement. The authors found that the isolator displacements from the equivalent-linear procedure underestimated those from the nonlinear analysis by $20 \%-50 \%$ on average. Thus, the minimum design displacements required by the code were not conservative for the strong ground motions, consistent with moderate earthquakes, used in their study. 
Since the ground motions in future earthquakes are uncertain, structural engineers cannot design a building for the specific ground motions that it will experience in its lifetime. Instead, structural engineers rely on building codes to define the types of ground motions that buildings must safely survive. The design response spectrum represents ground motions from events that are deemed likely to excite buildings in their assumed lifetime. From the design spectrum, structural engineers determine the minimum design forces that buildings must withstand. The building code also acknowledges that unusually large earthquakes occur in or near urban areas. The 2006 IBC describes the maximum considered earthquake (MCE) as "the most severe earthquake effects considered in this code" and defines the MCE as 1.5 times the design response spectrum (International Code Council, 2006). In an earthquake consistent with the MCE, structural engineers acknowledge that buildings will sustain significant damage to structural systems and building contents. However, the buildings may collapse-either partially or totally-only in ground motions that exceed the MCE (Hamburger, 2003). The design of MRFs like the ones in this study is consistent with this philosophy. The design of baseisolated buildings in the San Francisco Bay Area requires the use of ground motions consistent with the MCE, not the standard design spectrum (Structural Engneering Institute [SEI], 2006). In this way, structural engineers design most buildings for likely earthquakes while acknowledging that a large, unusual event will test the limits of the lateral force resisting systems.

The purpose of the study described in this article is to predict the response of some long-period buildings to scenario and hypothetical earthquakes in the San Francisco Bay Area. We apply ground motions from simulations of the 1989 Loma Prieta and large, northern San Andreas fault events (including the 1906 San Francisco earthquake) to steel MRF and base-isolated building models. We evaluate the effect on overall building performance of rupture direction, MRF building strength and weld state, and base-isolation system period and damping. We use response spectra to compare the spectral accelerations predicted in the magnitude 7.8 earthquakes to the 1994 UBC, 1997 UBC, and 2006 IBC design response spectra. This study continues the work of Hall and Challa (1995), Heaton et al. (1995), and Hall (1998) by considering long-period building response to recent simulations of ground motions from great earthquakes on a large geographical region.

Our analysis is limited in several ways. We only consider a few realizations of possible future great earthquakes. The next great northern San Andreas earthquake will almost certainly be different than our scenario and hypothesized events. Nonetheless, these events seem plausible because they are compatible with the current understanding of the 1906 San Francisco earthquake. Our study is also limited because we only consider several idealized building models. The buildings we consider are likely not the most vulnerable buildings in our considered earthquakes. We choose these buildings because their analysis is presently accessible to us. Furthermore, they are examples of very flexible structures. Increasing a building's flexibility can help to limit the stress in a building subjected to high-frequency ground motions, which may result from moderately sized earthquakes. However, extremely flexible structures may experience very large deformations in the large long-period ground motions produced by unusual great earthquakes.

\section{Description of Ground Motions}

Aagaard, Brocher, Dolenc, Dreger, Graves, Harmsen, Hartzell, Larsen, and Zoback (2008) and Aagaard, Brocher, Dolenc, Dreger, Graves, Harmsen, Hartzell, Larsen, McCandless, et al. (2008) simulated ground motions for the 1989 Loma Prieta earthquake, the 1906 San Francisco earthquake, and seven large hypothetical northern San Andreas fault events. In this study, we use time histories from four of these ground-motion simulations: the 1989 Loma Prieta scenario earthquake with the Wald source model; the 1906 San Francisco scenario earthquake (with an epicenter west of San Francisco and $3 \mathrm{~km}$ offshore); and two hypothetical earthquakes with the same slip distribution as the 1906 San Francisco scenario, SongModHypoC (with an epicenter near Bodega Bay, north of San Francisco) and SongModHypoS (with an epicenter near San Juan Bautista, south of San Francisco). We refer to the last two simulations as the magnitude 7.8 Bodega Bay and San Juan Bautista hypothetical earthquakes.

We use ground motions on an area 250 by $110 \mathrm{~km}$ that includes the southern half of the magnitude 7.8 ruptures. We select ground-velocity time histories at sites on several grids, with major urban areas gridded at higher resolutions. This sampling generates ground motions at 4945 sites. Figure 1 shows the simulation domain, regional geography, and urban areas (as defined in the 2000 census). Because this study considers plausible earthquakes on the northern San Andreas fault, which may damage long-period buildings, we focus our attention on currently urbanized locations. The total urban area is $3266 \mathrm{~km}^{2}$, and this includes urban areas at distances $60 \mathrm{~km}$ from the fault, specifically the East Bay, Santa Rosa, and Concord. Of course, only urban areas on the San Francisco peninsula or near San Jose are close to the San Andreas fault, and some sites in our urban areas are not suitable for the buildings we consider. When we report results, we consider damage on the entire urban area, and on urban areas in the cities of Oakland, San Francisco, San Jose, and Santa Rosa.

The ground-motion simulations include the local threedimensional geologic structure via three-dimensional geologic (Jachens et al., 2006) and seismic velocity (Brocher et al., 2006) models. The bandwidth of the simulations is limited to periods of $2.0 \mathrm{sec}$ and longer (frequencies of $0.5 \mathrm{~Hz}$ and lower). Aagaard limits the minimum shear-wave speed to $700 \mathrm{~m} / \mathrm{sec}$, so the simulated ground motions do not include amplification and nonlinear effects from soft near- 


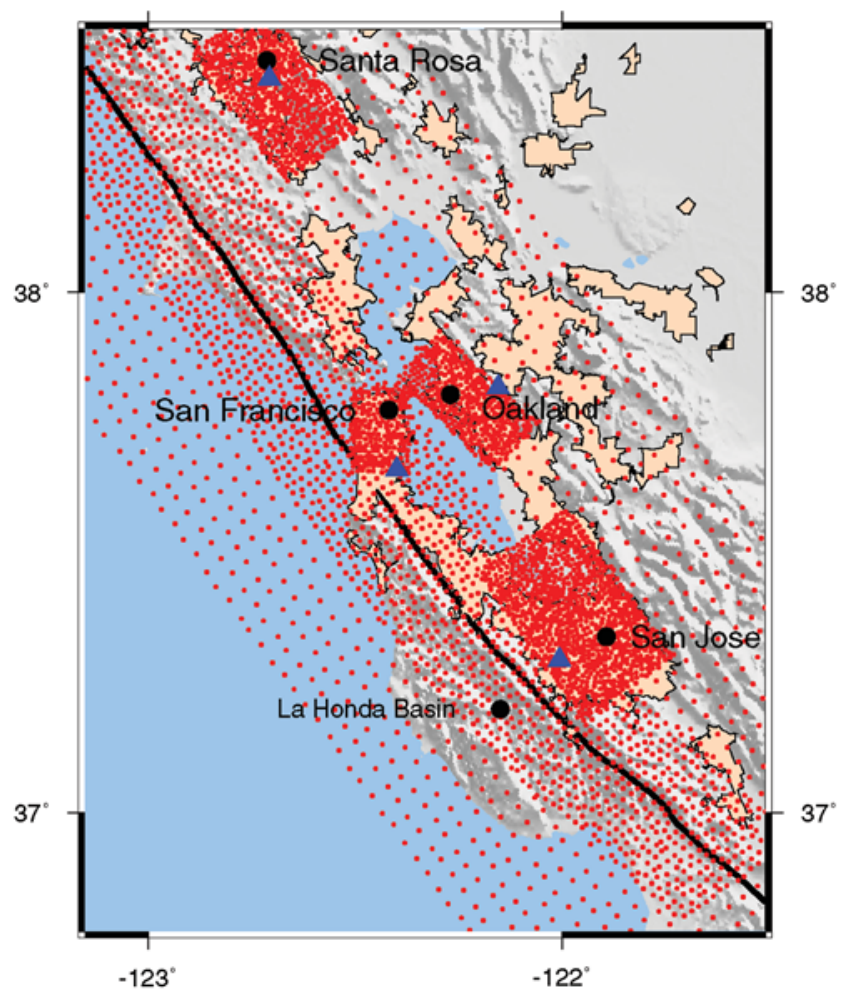

Figure 1. The San Francisco Bay Area has a large urban area near the San Andreas fault (heavy black line). Light orange shading highlights the urban areas that include $97 \%$ of the region's population. (In subsequent maps, a solid black line bounds the urban areas.) Red dots indicate the sites with simulated ground motion; some sites are located under water, but we do not include the results from these sites in this article. Blue triangles locate sites for response spectra presented in Figure 12.

surface sediments. The thin sedimentary deposits and artificial fill around the immediate perimeter of the San Francisco Bay are well recognized as an important issue when assessing seismic hazard (e.g., Lawson, 1908; Hough et al., 1990; Dobry et al., 2000). Because we do not include the amplification effect of these sediments (bay mud) or fill on the ground motions, the building responses in these areas may be considered a lower bound. To further complicate the interpretation of soft-soil sites, the designs of our buildings only meet or exceed the 1994 UBC for zone four and stiff soils. Buildings designed for very soft soils, such as bay mud, may be significantly different than the designs used in our study.

Figures 2 and 3 show the peak ground displacements and velocities, respectively, for the earthquake simulations. Aagaard, Brocher, Dolenc, Dreger, Graves, Harmsen, Hartzell, Larsen, McCandless, et al. (2008) noted that they believe errors in the seismic velocity model lead to overestimation of the ground motions in the La Honda basin in the Santa Cruz mountains, southwest of San Jose. (The La Honda basin is not included in our urban area. See Fig. 1.)
Compared to observations in the Loma Prieta earthquake, the overestimation in the ground motions was 1-2 modified Mercalli intensity units.

\section{Twenty-Story, Steel MRF Buildings}

\section{Description of Building Models}

A 20-story, steel, welded, MRF building is one example of a long-period building. This building is susceptible to long-period ground motions (Heaton et al., 1995), but it is not representative of every tall building. We choose to study a 20-story building, in part, because steel MRF buildings shorter and taller than approximately 20 stories tend to be stronger than this building. Taller buildings use different lateral-force-resisting systems to withstand larger wind loads, and so taller buildings require specialized design and analysis. Shorter buildings tend to have a larger base shear at yield, making them stronger than 20 -story buildings. Also, the fundamental frequency of shorter buildings is outside the frequency content of the simulated ground motions in this study. The design natural frequency of a 20-story building (approximately $0.4-0.5 \mathrm{~Hz}$ ) is in the frequency range of the ground motions. The 20-story steel MRF building models used in this study are regular and rectangular. Figure 4 shows the dimensions of the models.

To study the effect of building strength and stiffness on seismic response, we employ models with two different designs. Hall (1997) designed the buildings according to the 1992 Japanese Building Code (JBC) and the 1994 UBC for seismic zone four and stiff soils. There are no soft stories in the MRF models. Both designs have moment-resisting joints on the perimeter of the floor plan and simple connections at interior joints, with one exception: on the center line of the JBC design, there are moment-resisting joints at the interior beam-column connections. Also, some beams and columns in the JBC design are larger than their counterparts in the UBC design, and some columns in the JBC design bend about their weak axis. Because of the strength and drift requirements of each building code, the JBC designs are stronger and stiffer than the UBC design for the same elevation and plan dimensions. We do not compare the building codes themselves nor suggest that existing buildings in the San Francisco Bay Area were designed according to the 1992 JBC provisions.

Hall (1998) compares the steel MRF building models' behavior to the 1997 UBC static lateral-force requirements. While the building designed to the 1994 UBC is conservative, it does not satisfy the 1997 UBC. The building designed to the JBC satisfies the 1997 UBC static lateral-force requirements for velocity-based near-source factors, $N_{v}$, less than or equal to 1.2. This near-source factor is less than or equal to 1.2 for sites greater than $10 \mathrm{~km}$ from any fault and for sites $5 \mathrm{~km}$ from a fault with maximum moment magnitude less than 7.0 and slip rate less than $5.0 \mathrm{~mm} / \mathrm{yr}$. While the models designed to the 1992 JBC satisfy the lateral force provisions 


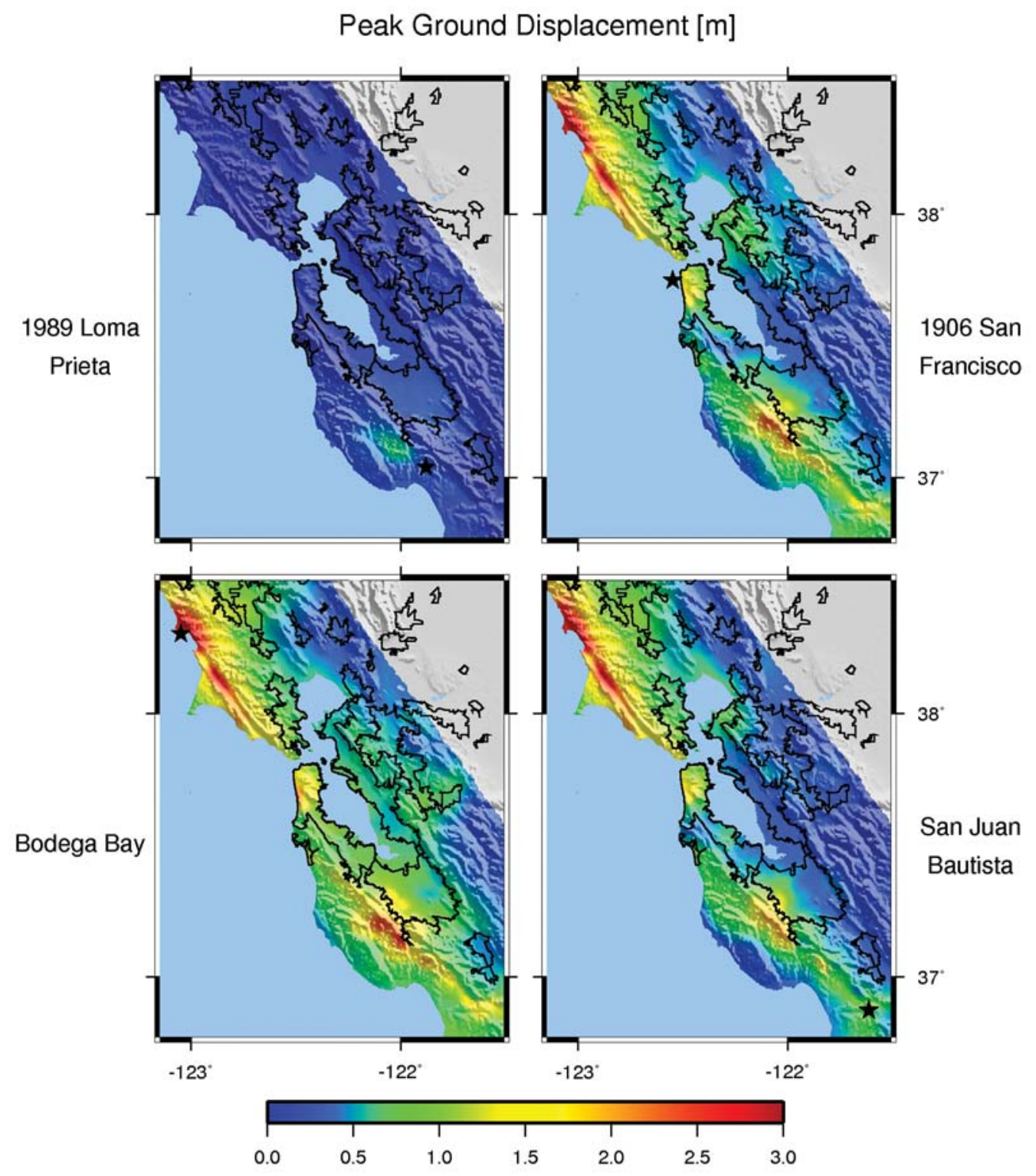

Figure 2. The 1989 Loma Prieta scenario earthquake generates moderate ground motions. The largest peak ground displacement is $0.67 \mathrm{~m}$. The peak ground motions in the magnitude 7.8 scenario and hypothetical earthquakes are significantly larger in amplitude and geographic extent. The largest peak ground displacements are $4.24 \mathrm{~m}$ (M 7.8 Bodega Bay), $4.26 \mathrm{~m}$ (1906 San Francisco), and $4.29 \mathrm{~m}$ (M 7.8 San Juan Bautista). The black stars locate the epicenters.

of the 1997 UBC at some sites in the San Francisco Bay Area, the models with brittle welds do not comply with the 1997 UBC. Again, the models designed to the 1992 JBC and 1994 UBC represent buildings with different combinations of strength and stiffness, which could have ductile or brittle welds.

Hall (1997) developed a finite-element algorithm specifically for steel-frame building models, and we use this algorithm to calculate MRF-model responses. A building model consists of planar frames coupled at the floors by an approximately rigid floor diaphragm. Several fibers constitute the cross section of each beam or column element, and each fiber behaves according to a nonlinear hysteretic steel model. This method explicitly models panel-zone behavior with a nonlinear hysteretic moment-shear strain model. The computational algorithm includes coordinate updating to account for $P-\Delta$ effects. (Under large lateral deformations, the columns are no longer approximately vertical. Thus, the columns carry vertical loads $P$ at a distance $\Delta$ from the vertical axis. $P-\Delta$ effects must be included in an analysis of frames with large deformations because the effect induces an additional moment carried by the columns.) The models do not capture out-of-plane or torsional motions. The building models have uniform mass and stiffness distributions in each story, and we assume uniform ground motion at the base of the buildings. Therefore, we do not expect a torsional component in the 


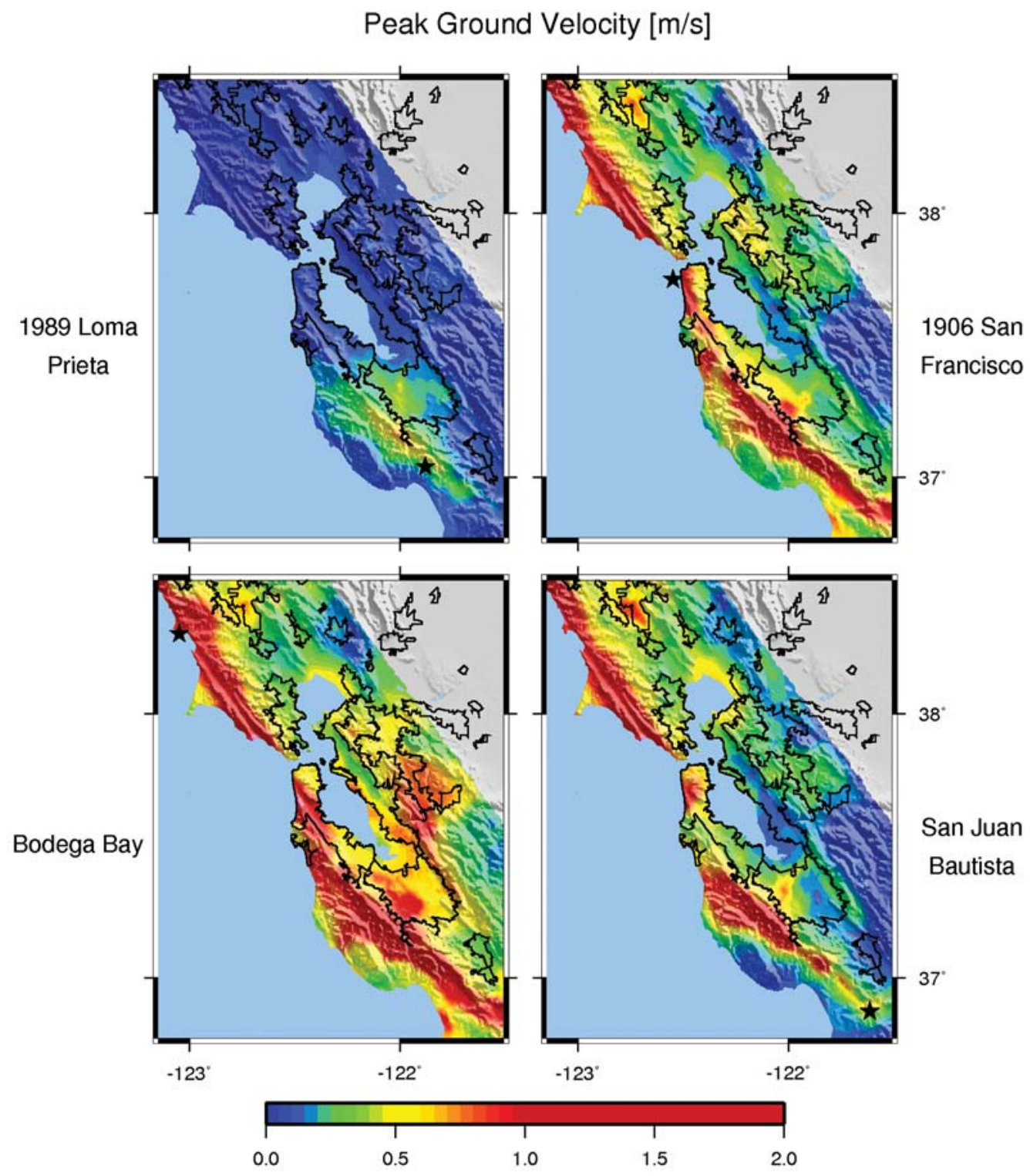

Figure 3. The three magnitude 7.8 earthquake simulations generate significantly larger peak ground velocities than those experienced in the 1989 Loma Prieta earthquake. The largest peak ground velocities are $0.82 \mathrm{~m} / \mathrm{sec}$ (1989 Loma Prieta), $3.03 \mathrm{~m} / \mathrm{sec}$ (M 7.8 Bodega Bay), $3.85 \mathrm{~m} / \mathrm{sec}$ (1906 San Francisco), and $3.85 \mathrm{~m} / \mathrm{sec}$ (M 7.8 San Juan Bautista). The black stars locate the epicenters.

building response. A planar-frame model is adequate for these simulations because it captures the important behaviors of these regular building models. In order to estimate the largest model responses for each ground motion, we apply the ground motion in the weakest orientation of the building: we orient the weak bending axis of the building perpendicular to the direction of the largest peak-to-peak ground velocity. We resolve the orthogonal horizontal components into this direction, and we apply the resultant horizontal and vertical time histories to the planar model.

The only deterioration mechanism in the MRF models is weld fracture. At each moment-resisting joint, a stochastic procedure assigns a fracture strain to the weld fibers, and the assignment is the same for all simulation sites. If the strain in the weld fiber exceeds the fracture strain, the fiber no longer carries tensile loads for the remainder of the simulation. The MRF models may have ductile welds $(P)$, which do not fracture, or brittle welds $(B)$, which fracture according to the following constraints. For the bottom beam flange at a moment-resisting joint, $20 \%$ of weld fibers fracture when the ratio of strain to yield strain, $\varepsilon / \varepsilon_{\text {yield }}$, is $0.7 ; 40 \%$ fracture when $\varepsilon / \varepsilon_{\text {yield }}=1 ; 20 \%$ fracture when $\varepsilon / \varepsilon_{\text {yield }}=10 ; 10 \%$ fracture when $\varepsilon / \varepsilon_{\text {yield }}=50 ;$ and $10 \%$ fracture when $\varepsilon / \varepsilon_{\text {yield }}=100$. For the top beam flanges, column splices, and column base-plate welds, $40 \%$ of weld fibers fracture when $\varepsilon / \varepsilon_{\text {yield }}=1 ; 30 \%$ fracture when $\varepsilon / \varepsilon_{\text {yield }}=10$; and $30 \%$ fracture when $\varepsilon / \varepsilon_{\text {yield }}=100$. Hall (1997) chose these ratios and distributions to approximate observed structural damage after the 1994 Northridge earthquake. Following Hall, we abbreviate the building code, height in stories, 


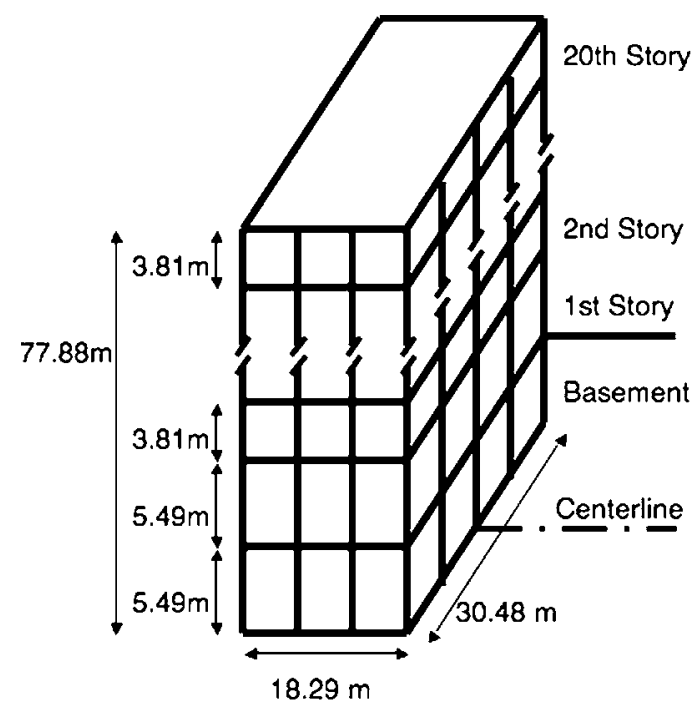

Figure 4. We use four 20-story steel MRF building models in our analysis. The MRF models share the same floor plan and dimensions. There are no soft stories in the design. The third story is most likely to show simulated collapse.

and weld state of the MRF models. For example, J20B denotes a 20-story, steel MRF building model designed to the JBC with brittle welds. The four building types we consider in this article are J20P, J20B, U20P, and U20B.

The period and base shear at yield are two commonly reported building parameters. The elastic first- and secondmode periods with damping are 3.4 and $0.90 \mathrm{sec}$, respectively, for the J20P model and are 4.1 and $1.1 \mathrm{sec}$, respectively, for the U20P model. Note that the ground motions' bandwidth includes the first-mode period but not the second-mode period. Engineers often use a pushover analysis to quantify characteristics of the building models. Important characteristics include the base shear when the building yields; the ultimate base shear; and the maximum amount of displacement supported by the frame as a fraction of the displacement at yield, or ductility. A pushover analysis applies an increasing, lateral force to the model until it loses all lateral-load-carrying capacity and the building collapses due to $P-\Delta$ instability. The simulation generates a pushover curve that relates the shear in the first floor columns to the lateral roof displacement. Figure 5 shows the pushover curves for the four models. The base shear at yield (as a fraction of the design weight) is approximately 0.12 for the J20P model and approximately 0.09 for the U20P model. The JBC building models are stronger than the UBC models, whereas the UBC models have a longer fundamental period.

\section{Response of Building Models}

We measure building response with the peak interstory drift ratio (IDR). The IDR quantifies the relative displacement of the two floors forming a story, as a ratio of the story height. The IDR indicates the amount of shear deformation,

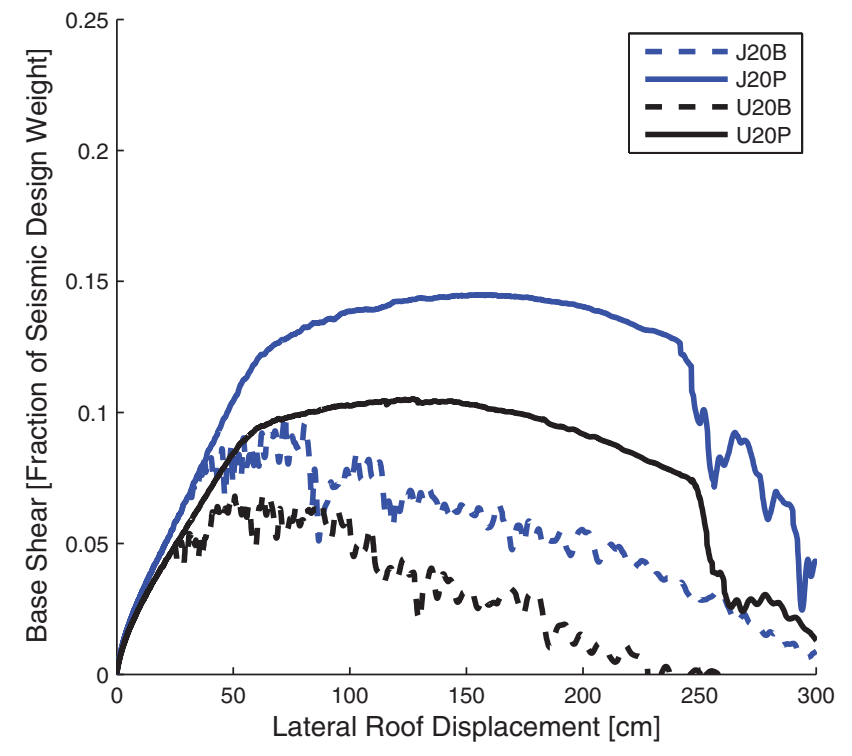

Figure 5. The pushover curves show the characteristic pushover responses of the steel MRF building models. The JBC buildings are stronger than the equivalent UBC buildings, as measured by the base shear at yield. The buildings with ductile welds have approximately the same ductility, or ratio between the lateral roof displacements at failure (approximately $240 \mathrm{~cm}$ ) to yield (approximately $60 \mathrm{~cm}$ ).

averaged over the story, in any story for the duration of the simulation.

The computational algorithm provides no direct measurement of partial or total collapse of the model. As a proxy measure, we use IDR. As the IDR increases, we assume that the building model's ability to remain standing decreases. Some ground motions induce forces in the building models that exceed their ability to resist lateral loads for the remainder of the simulation. The simulated responses show that no MRF building model retains any lateral-load-carrying capacity after registering an IDR of 0.15 . Thus, we deem the simulation result a simulated collapse when the IDR exceeds 0.15 . Such large responses violate the small strains and rotations assumptions of the finite elements, so the simulations do not give valid results for larger deformations.

Figures 6-9 show MRF model responses to the four scenario earthquakes. Each of the four panels in a figure shows the response of one building type at all locations in the simulation domain. Also, ground motions in areas with soft soils do not include site amplification. The responses of longperiod buildings in those areas may be a lower bound. The colors on the maps are consistent with the structural performance levels for steel moment frames defined by the Federal Emergency Management Agency report 356 (FEMA 356; American Society of Civil Engineers [ASCE], 2000). Areas colored blue indicate elastic or mild inelastic response $(0.007<$ IDR $<0.025$, immediate occupancy). Areas colored green to yellow indicate moderate to severe inelastic deformation; a building located in these areas would 


\section{Peak Inter-Story Drift Ratio 1989 Loma Prieta Earthquake}

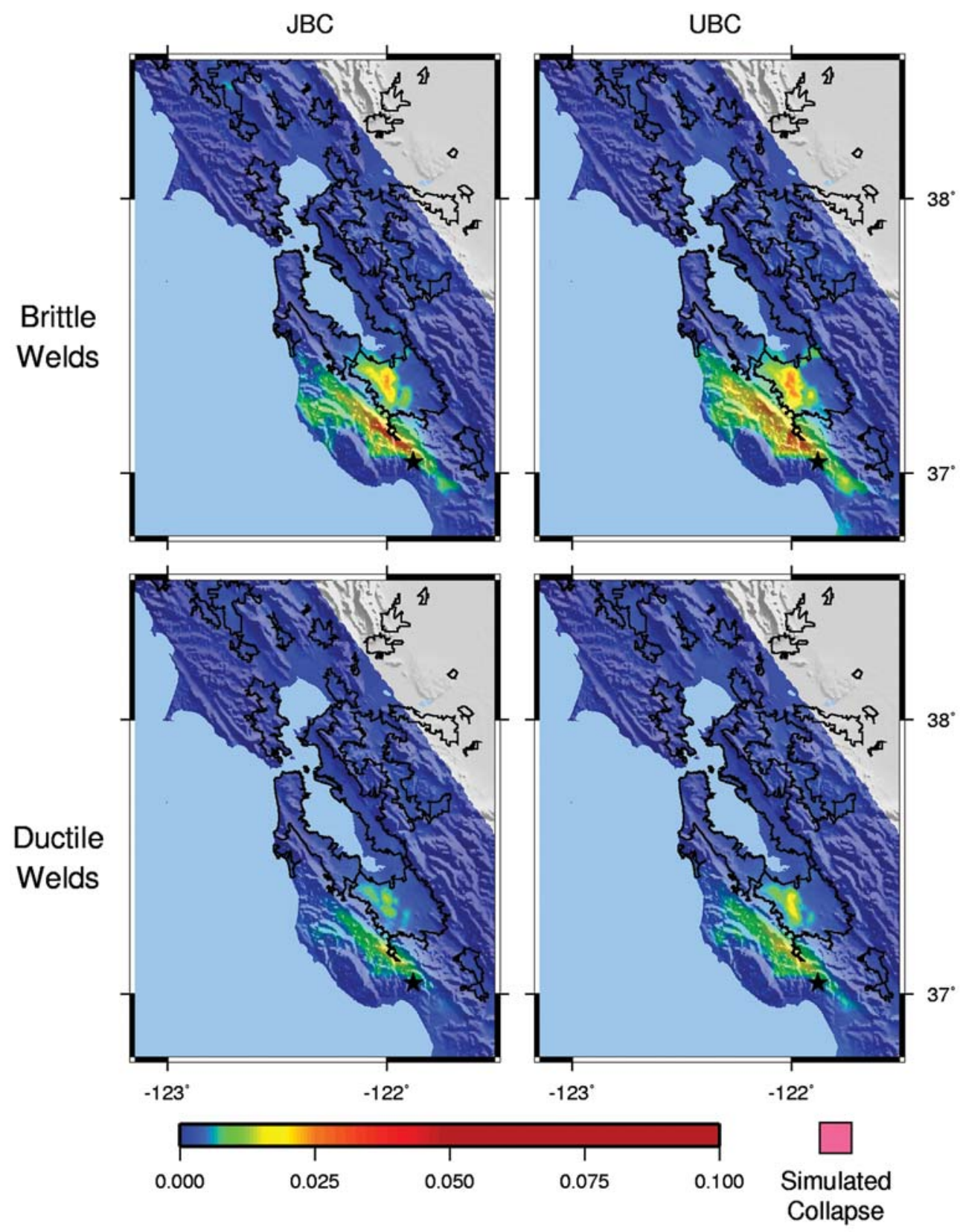

Figure 6. The 1989 Loma Prieta scenario earthquake induces small interstory drifts in the MRF building models. The largest building responses would have been observed in the urban area of the Santa Clara Valley, near San Jose. (See text for physical interpretation of map coloring.)

need structural repairs for reoccupation following the earthquake $(0.025<\mathrm{IDR}<0.05$, life safety). Areas colored orange to red indicate the potential for partial or total collapse (IDR $>0.05$, collapse prevention); a building in these areas may be a total loss. Areas colored pink indicate that the building models lost all lateral-load-carrying capacity in the simulation (simulated collapse).
Tables 1 and 2 record the MRF building model responses. Table 1 shows the percentage of areas within the San Francisco Bay region on which the model responses exceed the FEMA 356 life safety level (IDR > 0.025). Table 2 shows the percentage of areas within the bay region on which the building models reach simulated collapse (IDR $>0.15$ ). In both tables, we report only model responses within urba- 


\section{Peak Inter-Story Drift Ratio Bodega Bay Hypothetical Earthquake}

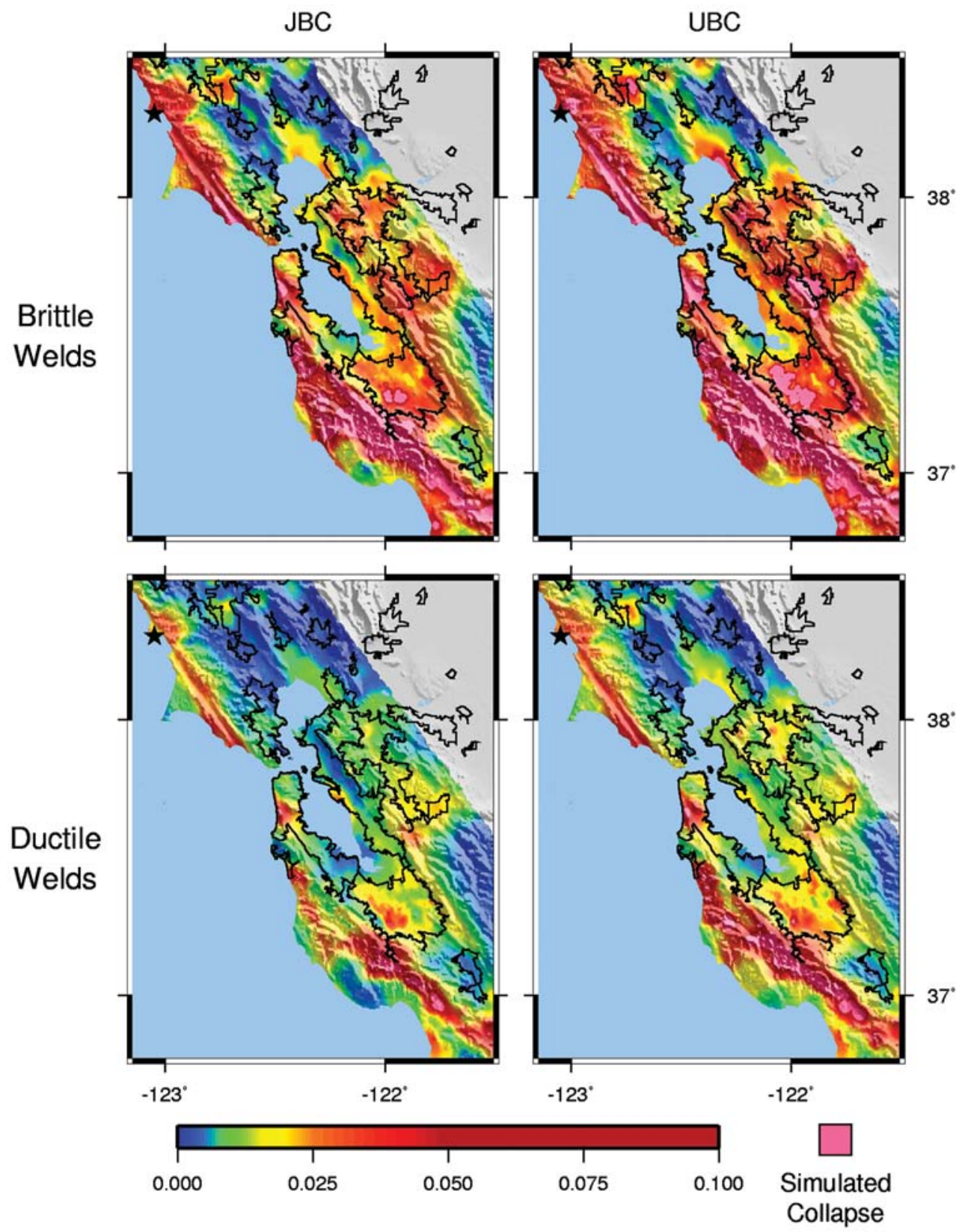

Figure 7. In the magnitude 7.8 Bodega Bay hypothetical earthquake, the rupture propagates north to south into the San Francisco Bay Area. Urban areas south of San Francisco and Oakland show large steel MRF building model responses. As in all scenarios, the stiffer, higher strength design tends to have responses smaller than those of the more flexible, lower strength design, and buildings with ductile welds outperform those with brittle welds. (See text for physical interpretation of map coloring.)

nized areas. Also, we report the areas of percent exceedance on all urban areas as well as the urban areas of the Oakland, San Francisco, San Jose, and Santa Rosa subdomains mapped in Figure 1.

The building responses to the 1989 Loma Prieta scenario earthquake are small. On most of the San Francisco Bay Area, the 20-story, steel MRF buildings remain elastic in the simulation. For example, the response of the more flexible, lower strength building with brittle welds exceeds the life safety level on $13 \mathrm{~km}^{2}$ of the entire urban area. Table 1 shows that, of the four major subdomains we consider, only San Jose has building responses that exceed life safety, and the areas of exceedance are small. Table 2 shows no simulated collapses of models in the urban areas. The Loma Prieta 


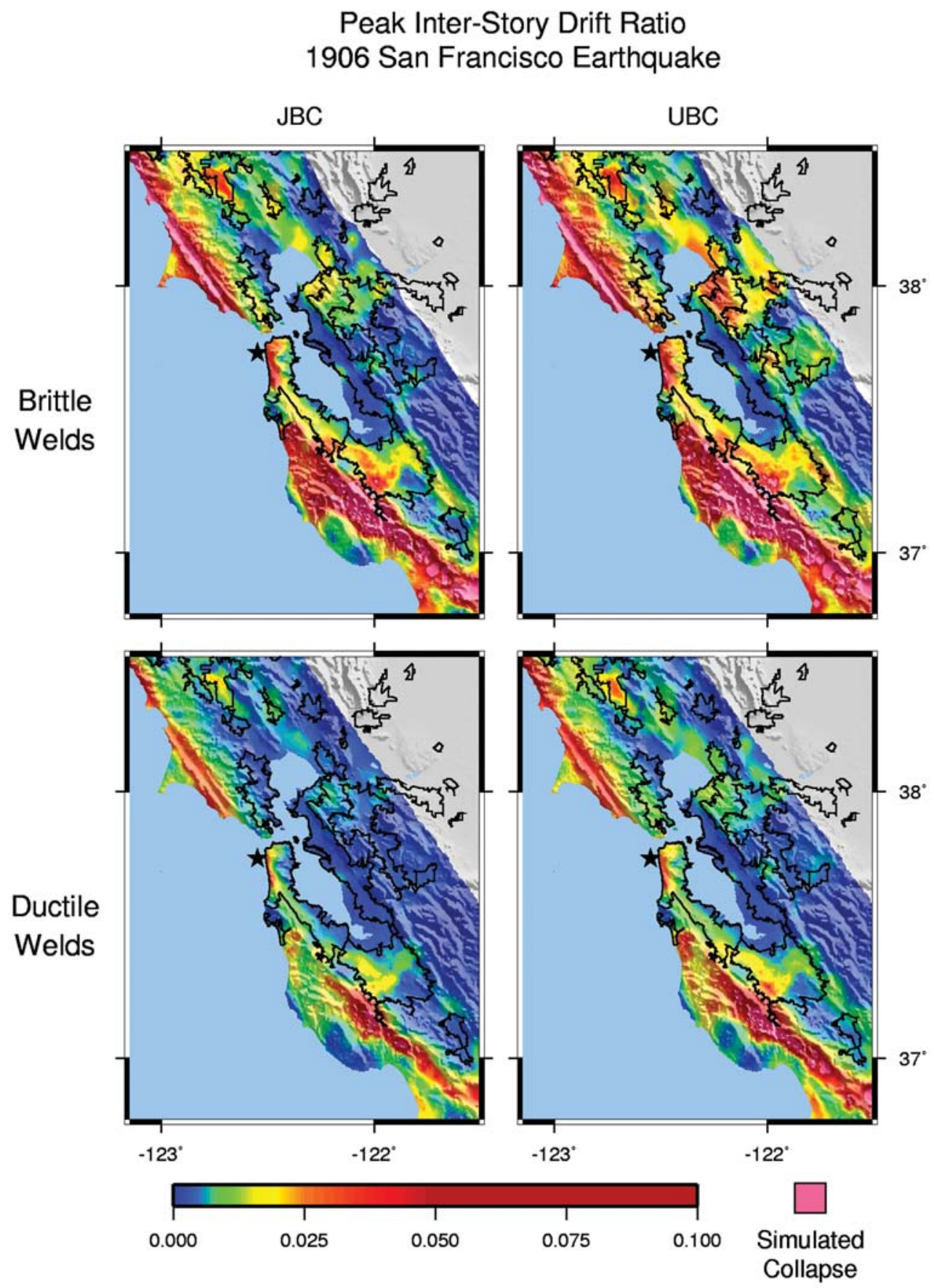

Figure 8. This simulation predicts MRF building responses in the 1906 San Francisco scenario earthquake. The hypocenter is located offshore and west of San Francisco, and the fault ruptures bilaterally. Most energy travels away from the city of San Francisco. Of the three magnitude 7.8 scenario and hypothetical earthquakes, this scenario tends to show the smallest responses in San Francisco. (See text for physical interpretation of map coloring.)

scenario is significantly less damaging in all parts of the San Francisco Bay Area than any of the three magnitude 7.8 simulations.

The stiffer, higher strength model with ductile welds performs better than the other three MRF models. The geographic extents of models with inelastic deformations and simulated collapses are both smaller for the stiffer, higher strength buildings than for the more flexible, lower strength buildings. For the magnitude 7.8 Bodega Bay hypothetical earthquake, the MRF building models with ductile welds exceed the life safety level on $10 . \%$ (U20P) and $4.6 \%$ (J20P) of the urban area; the same models with brittle welds show the same level of response on 54\% (U20B) and 36\% (J20B) of the urban area. The responses of the stiffer, higher strength mod- 


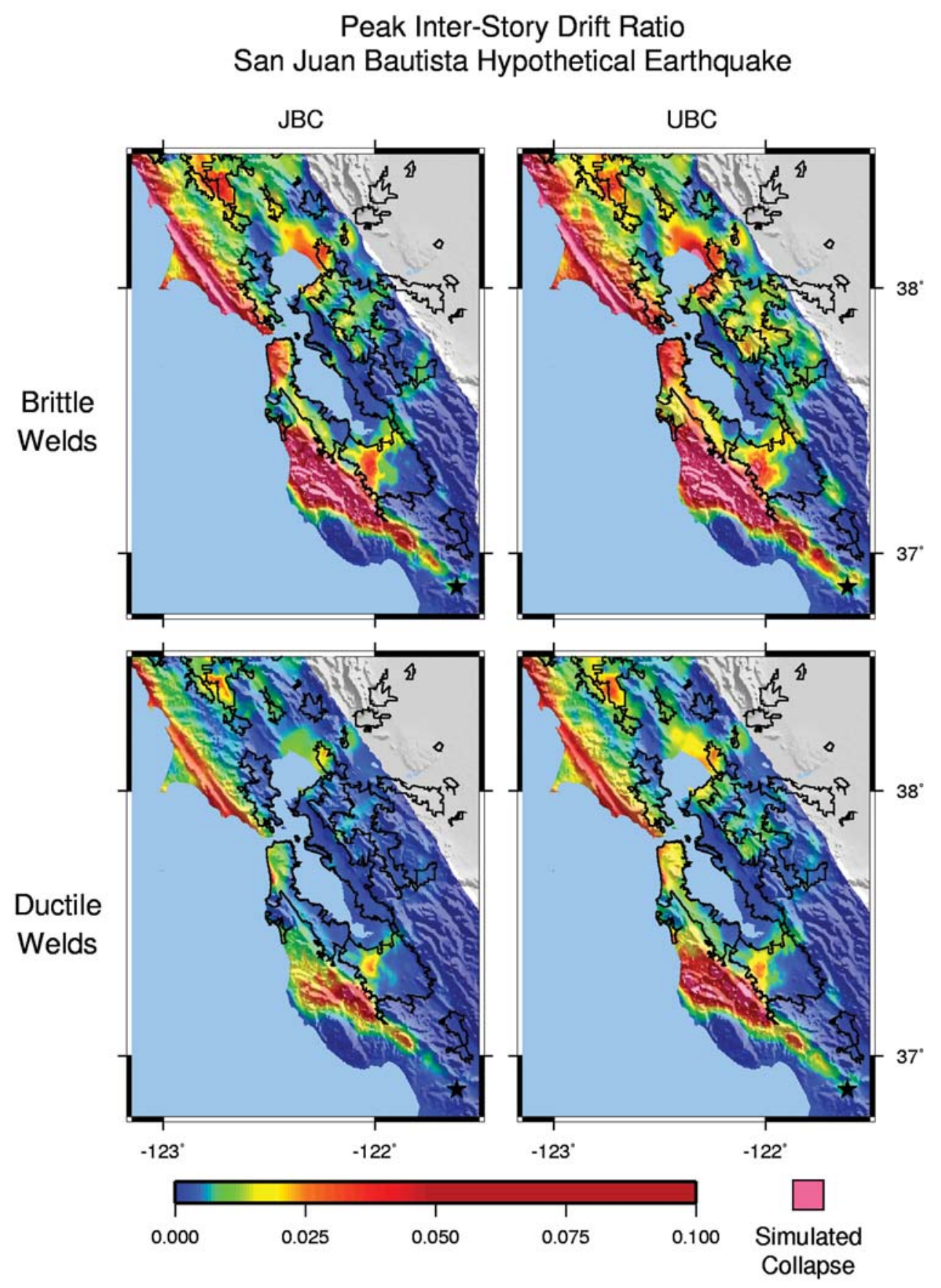

Figure 9. Considering the urban area in the magnitude 7.8 San Juan Bautista hypothetical earthquake, the largest building responses occur in San Francisco. Urban areas outside San Francisco tend to have the smallest responses of all three magnitude 7.8 earthquakes. This scenario produces the fewest simulated collapses in the urban areas. (See text for physical interpretation of map coloring.)

els exceed the life safety level on smaller areas than the responses of the more flexible, lower strength models. Not surprisingly, MRF models with ductile welds perform better than models with brittle welds.

While all of the magnitude 7.8 earthquakes produce large long-period ground motions, the results from the magnitude 7.8 Bodega Bay and San Juan Bautista hypothetical earthquakes are different than those of the 1906 San Francis- co scenario. The Bodega Bay hypothetical earthquake (with hypocenter north of San Francisco and unilateral rupture to the south) is generally the most severe of the three magnitude 7.8 earthquakes. For the entire urban area and the Oakland and San Jose subdomains, the Bodega Bay hypothetical earthquake causes the largest percent areas of life safety exceedance for all four MRF models. This earthquake also produces the largest percent areas of simulated collapse for all 
Table 1

Percent of Urban Areas on which Building Response Threatens Life Safety

\begin{tabular}{|c|c|c|c|c|c|}
\hline Domain & Simulation & $\mathrm{J} 20 \mathrm{~B}$ & $\mathrm{~J} 20 \mathrm{P}$ & U20B & U20P \\
\hline \multirow[t]{4}{*}{ Entire urban outline } & 1989 Loma Prieta & 0.079 & 0 & 0.40 & 0 \\
\hline & M 7.8 Bodega Bay & 36 & 4.6 & 54 & 10. \\
\hline & 1906 San Francisco & 9.3 & 0.99 & 15 & 3.1 \\
\hline & M 7.8 San Juan Bautista & 11 & 0.95 & 17 & 2.4 \\
\hline \multirow[t]{4}{*}{ Oakland subdomain } & 1989 Loma Prieta & 0 & 0 & 0 & 0 \\
\hline & M 7.8 Bodega Bay & 18 & 1.6 & 48 & 0.20 \\
\hline & 1906 San Francisco & 0 & 0 & 0 & 0 \\
\hline & $M 7.8$ San Juan Bautista & 0 & 0 & 0 & 0 \\
\hline \multirow[t]{4}{*}{ San Francisco subdomain } & 1989 Loma Prieta & 0 & 0 & 0 & 0 \\
\hline & M 7.8 Bodega Bay & 48 & 18 & 69 & 35 \\
\hline & 1906 San Francisco & 39 & 12 & 49 & 18 \\
\hline & $M 7.8$ San Juan Bautista & 63 & 6.8 & 92 & 13 \\
\hline \multirow[t]{4}{*}{ San Jose subdomain } & 1989 Loma Prieta & 0.20 & 0 & 1.7 & 0 \\
\hline & M 7.8 Bodega Bay & 64 & 11 & 83 & 26 \\
\hline & 1906 San Francisco & 14 & 0.018 & 18 & 3.8 \\
\hline & $M 7.8$ San Juan Bautista & 11 & 0.51 & 14 & 1.6 \\
\hline \multirow[t]{4}{*}{ Santa Rosa subdomain } & 1989 Loma Prieta & 0 & 0 & 0 & 0 \\
\hline & M 7.8 Bodega Bay & 18 & 0 & 38 & 3.1 \\
\hline & 1906 San Francisco & 25 & 0 & 25 & 8.6 \\
\hline & $M 7.8$ San Juan Bautista & 38 & 5.7 & 27 & 11 \\
\hline
\end{tabular}

FEMA 356 defines a level of life safety for steel MRF buildings at an interstory drift ratio of 0.025 . At this level, a building would require structural repairs, but partial or total collapse is unlikely. Depending on the earthquake and building type, the simulated building responses may exceed the life safety level on a limited or broad portion of the urban area. The Bodega Bay hypothetical earthquake especially causes damage in large parts of the San Francisco Bay urban area. The entire urban area in the simulation domain is $3266 \mathrm{~km}^{2}$.

Table 2

Percent of Urban Areas on which Building Models Collapse

\begin{tabular}{|c|c|c|c|c|c|}
\hline Domain & Simulation & $\mathrm{J} 20 \mathrm{~B}$ & $\mathrm{~J} 20 \mathrm{P}$ & U20B & U20P \\
\hline \multirow[t]{4}{*}{ Entire urban outline } & 1989 Loma Prieta & 0 & 0 & 0 & 0 \\
\hline & M 7.8 Bodega Bay & 1.7 & 0.049 & 6.6 & 0.24 \\
\hline & 1906 San Francisco & 0.29 & 0 & 0.67 & 0.00092 \\
\hline & M 7.8 San Juan Bautista & 0.092 & 0 & 0.42 & 0 \\
\hline \multirow[t]{4}{*}{ Oakland subdomain } & 1989 Loma Prieta & 0 & 0 & 0 & 0 \\
\hline & M 7.8 Bodega Bay & 0 & 0 & 0 & 0 \\
\hline & 1906 San Francisco & 0 & 0 & 0 & 0 \\
\hline & M 7.8 San Juan Bautista & 0 & 0 & 0 & 0 \\
\hline \multirow[t]{4}{*}{ San Francisco subdomain } & 1989 Loma Prieta & 0 & 0 & 0 & 0 \\
\hline & M 7.8 Bodega Bay & 8.8 & 0.89 & 24 & 4.1 \\
\hline & 1906 San Francisco & 0.11 & 0 & 1.7 & 0 \\
\hline & M 7.8 San Juan Bautista & 1.3 & 0 & 1.6 & 0 \\
\hline \multirow[t]{4}{*}{ San Jose subdomain } & 1989 Loma Prieta & 0 & 0 & 0 & 0 \\
\hline & M 7.8 Bodega Bay & 3.2 & 0 & 15 & 0.033 \\
\hline & 1906 San Francisco & 0.031 & 0 & 0.97 & 0 \\
\hline & $M 7.8$ San Juan Bautista & 0 & 0 & 0.59 & 0 \\
\hline \multirow[t]{4}{*}{ Santa Rosa subdomain } & 1989 Loma Prieta & 0 & 0 & 0 & 0 \\
\hline & M 7.8 Bodega Bay & 0 & 0 & 4.0 & 0 \\
\hline & 1906 San Francisco & 0 & 0 & 0 & 0 \\
\hline & M 7.8 San Juan Bautista & 0.069 & 0 & 0.069 & 0 \\
\hline
\end{tabular}

Some ground motions cause exceedance of the lateral force resisting ability of the MRF models (simulated collapse). This level is much greater than the life safety performance level defined by FEMA 356. MRF models with brittle welds show simulated collapses on a greater area than models with ductile welds. The response of the stiffer, higher strength models exceed the life safety level on smaller areas than that of the more flexible, lower strength models. The entire urban area in the simulation domain is $3266 \mathrm{~km}^{2}$. 
MRF building models and all subregions of the San Francisco Bay Area. The epicenter of the 1906 scenario earthquake is due west of San Francisco, and the fault ruptures bilaterally. In this simulation, there are no significant directivity pulses in the city of San Francisco. Compared to the other magnitude 7.8 simulations, the 1906 scenario generates some of the smallest percent areas of life safety exceedance in San Francisco. The San Juan Bautista hypothetical earthquake (with hypocenter south of San Francisco and unilateral rupture to the north) produces some of the smallest percent areas of life safety exceedance of the three magnitude 7.8 simulations. One important exception to this trend is the responses for the models with brittle welds in the San Francisco subdomain: for the J20B model, 63\% of the San Francisco area exceeds the life safety level, and for the U20B model, $92 \%$ of the San Francisco area exceeds the life safety level. Another exception to the smaller responses in the San Juan Bautista hypothetical earthquake is in the Santa Rosa subdomain: this earthquake generates the largest percent area of life safety exceedance in Santa Rosa for all building models except U20B. Of the magnitude 7.8 simulations, the Bodega Bay hypothetical earthquake causes the most damage to 20-story, steel MRF buildings in the modern urban area, whereas the San Juan Bautista hypothetical earthquake tends to cause the least damage.

\section{Base-Isolated Buildings}

In the past several decades, engineers have accepted the method of inserting a thin, flexible layer between a building's superstructure and foundation as a good means to reduce seismic risk in historic and modern buildings. During an earthquake, much of the isolated building's deformation concentrates in the isolation layer, and the isolated superstructure experiences smaller deformations than an unisolated building. However, near-source ground motions from earthquakes with large slips may cause isolator displacements that exceed the isolator capacity (Heaton et al., 1995). In this study, we estimate the differential displacement between the building superstructure and its foundation.

A well-isolated base-isolated building can be modeled adequately by a single-degree-of-freedom (SDOF) system. For a nonisolated building, a modal analysis accurately predicts linear deformations as a superposition of the individual modal responses. Adding base isolators to a building introduces three new modes (two translational and one rotational) to the structural analysis. If the isolators are sufficiently flexible, then these new modes have significantly longer periods than the fundamental period of the superstructure alone. In this case, Chopra (2001) shows that the fundamental mode of the isolated system can be modeled by an SDOF oscillator. The mass of the oscillator is that of the superstructure, and the restoring force and damping of the oscillator models the behavior of the isolators. In this way, an SDOF system estimates the response of a base-isolated system.
The behavior of base isolators in large earthquakes is nonlinear. The two most common types of isolators are rubber isolators, which are typically short, cylindrical pads with alternating layers of rubber and steel plates; and frictionpendulum isolators, which typically consist of a small steel bearing that slides on a concave, hemispherical surface. An accurate and precise model of isolator behavior must include nonlinear dependencies on isolator deformation (for example, displacement) and/or deformation velocity. In rubber isolators, either fillers in the rubber or a small lead cylinder, which yields with ductility at significant strains, provides large amounts of viscous damping. For small strains, the rubber in laminated bearings strain softens, but at very large strains, the rubber strain hardens. Whereas high-hysteresis rubber bearings have approximately linear viscous damping, lead-core laminated bearings undergo plastic deformation similar to that from dry friction damping. In contrast, the dynamic friction of sliding surfaces provides the damping in friction-pendulum isolators. These isolators induce a building motion like that of a gravitational pendulum. Hence, the restoring force is approximately linear for the range of motions encountered in building applications. The bearing friction, however, is nonlinear, dry friction: the isolator is very stiff until it overcomes the static friction, and then friction is a constant force in the opposite direction of sliding velocity. The damping in isolation systems is nonlinear and significantly larger than damping in traditional steel-frame buildings.

\section{Description of Building Models}

Despite the nonlinear behavior of the isolators, a baseisolated system can be modeled as an equivalent-linear system with the equivalent-linear period and damping dependent on the amplitude of isolator displacement. The fundamental period of an equivalent-linear system is usually $T=2 \pi \sqrt{m / k_{e}}$, where $m$ is the superstructure mass, and $k_{e}$ is the effective stiffness defined as the ratio of the bearing restoring force to the displacement, measured at the maximum expected displacement. Ryan and Chopra (2004b) studied the difference between maximum isolator displacements predicted by nonlinear and equivalent-linear SDOF models for 20 near-source ground motions recorded from four earthquakes. To approximate the characteristics of lead-rubber isolators, they used a bilinear strain-softening model. They found that the median ratio of maximum isolator displacement from the bilinear model to that of the equivalent-linear model monotonically increased from 1.3 at $2 \mathrm{sec}$ to 1.5 at $4 \mathrm{sec}$. Also, the equivalent-linear displacements were log-normally distributed about the median values with a standard deviation of about $46 \%$ of the nominal value. In a related study, Ryan and Chopra (2004a) investigated the difference between bilinear models of friction-pendulum isolators and equivalent-linear SDOF models. Here, they found that the median ratio of maximum isolator displacement from the bilinear model to that of the equivalent-linear model 
monotonically increased from 1.1 at $2 \mathrm{sec}$ to 1.4 at $4 \mathrm{sec}$. The standard deviation in this case was about $50 \%$ of the nominal value. Based on these results, equivalent-linear models of base-isolation systems tend to underestimate the maximum isolator displacements predicted from more complete, nonlinear models of the same buildings.

In order to estimate the isolator displacements during our scenario and hypothetical earthquakes, we compute the maximum displacement of an equivalent-linear SDOF system. We assume that the fundamental period of the base-isolation system is a few times larger than the fundamental period of the superstructure. We further assume that the isolator behavior can be approximated by linear springs and viscous damping. Under these assumptions, the maximum isolator displacement is the displacement response spectral value at the appropriate period and damping. We simulate systems with periods of 2 and $3 \mathrm{sec}$ with isolator damping at $10 \%$ and $20 \%$ of critical.

Base-isolation systems with 3-sec equivalent-linear periods and $10 \%$ damping seem to be common for existing systems in the San Francisco Bay Area. For example, the 18story Oakland City Hall was retrofit with lead-rubber bearings, and its fundamental period is $2.85 \mathrm{sec}$ (Walters, 2003). If the isolator displacement exceeds $0.51 \mathrm{~m}$, the superstructure would impact the foundation (Kelly, 1998). The international terminal of the San Francisco Airport was constructed with friction-pendulum isolators. This system's fundamental period is $3 \mathrm{sec}$, and the maximum displacement of each bearing is $0.51 \mathrm{~m}$ (EPS, 2003).

\section{Response of Building Models}

Figures 10 and 11 show the isolator displacements of our 2- and 3-sec linear base-isolation building models for the magnitude 7.8 Bodega Bay and San Juan Bautista hypothetical earthquakes. For each period, the model has viscous damping at $10 \%$ or $20 \%$ of critical. Although equivalent damping values are typically less than $10 \%$, we include $20 \%$ damping to provide insight into the effect of including supplemental damping devices. The map colorings indicate the maximum isolator displacement. (Note that we choose different color scales for the 2- and 3-sec isolators: longerperiod systems typically have larger design maximum displacements.) Based on the work of Ryan and Chopra (2004a,b) we expect that the maximum displacements of nonlinear isolators are 10\%-30\% larger than the maximum displacements of our linear isolators.

The equivalent-linear base-isolation simulations predict large isolator displacements in the hypothetical earthquakes. The simulated ground motions are particularly rich in long periods; the 3-sec model shows larger isolator displacements than the $2 \mathrm{sec}$, and the larger responses span a greater area. As expected, the $20 \%$ damped models show smaller isolator displacements than the 10\% damped. East of the San Francisco Bay, the Bodega Bay earthquake induces isolator displacements two to five times larger than those from the San
Juan Bautista earthquake, whereas north of the Bay, the San Juan Bautista earthquake generates isolator displacements up to twice those from the Bodega Bay earthquake.

Using spectral displacement to model base-isolated building response has the advantage that it is a simple analysis. A more advanced analysis requires an appropriate nonlinear model of isolator behavior under large lateral deformation and a multi-degree-of-freedom model of the superstructure. The spectral displacement results are expected to provide a conservative estimate of isolator displacements; we expect greater isolator displacements in the areas of large ground motions. Nonetheless, as recorded in Table 3, the spectral displacement analysis shows large displacements in the urban areas. The large ground motions used in this study should be applied to more sophisticated base-isolation models to quantify how much the spectral displacements underestimate more sophisticated predictions of isolator displacements.

\section{Response Spectra}

Ground motions like those from the three magnitude 7.8 simulations are severe and represent part of the seismic hazard in the San Francisco Bay Area. Because the San Andreas fault produced the 1906 San Francisco earthquake, it is capable of producing an earthquake at least as large as magnitude 7.9. The two hypothetical earthquakes included in this article are variations on the 1906 scenario. Thus, we believe these hypothetical earthquakes are reasonable simulations to consider for the San Francisco Bay Area. The next great earthquake clearly will be none of these three, but given the uncertainty of the future, we believe simulations like these should be considered in the seismic hazard of the San Francisco Bay Area.

The large number of sites in this study precludes displaying the response spectrum for each site. Figure 12 shows standard response spectra for selected sites in the urban area. We also present nonstandard response spectra to capture the character of the spectra at all sites in the urban area of our simulation domain. We calculate the pseudospectral acceleration (PSA) for $2-5$-sec periods at all sites. Then, at each period, we select the PSA values that are exceeded on $1 \%$, $3 \%, 10 \%$, and $25 \%$ of the urban area. For example, the PSA at 2-4 sec exceeds $0.5 g$ on $3 \%$ of the urban area in the Bodega Bay hypothetical earthquake. In this case, 3\% of the urban area experiences a PSA greater than $0.5 \mathrm{~g}$. Figure 13 shows our response spectra for the three magnitude 7.8 earthquakes, the 1994 UBC design spectrum, and the upper and lower bounds on the 1997 UBC and 2006 IBC design spectra for sites in the Bay Area. The response spectra have damping at $5 \%$ of critical, and the site class for the design spectra is D, or stiff soil.

The design response spectra defined by the 2006 IBC are similar to our spectra of the three magnitude 7.8 earthquakes. The design spectrum for a particular site depends on the spectral acceleration at long periods assigned to that site 


\section{Spectral Displacement [m] Period is 2 seconds}

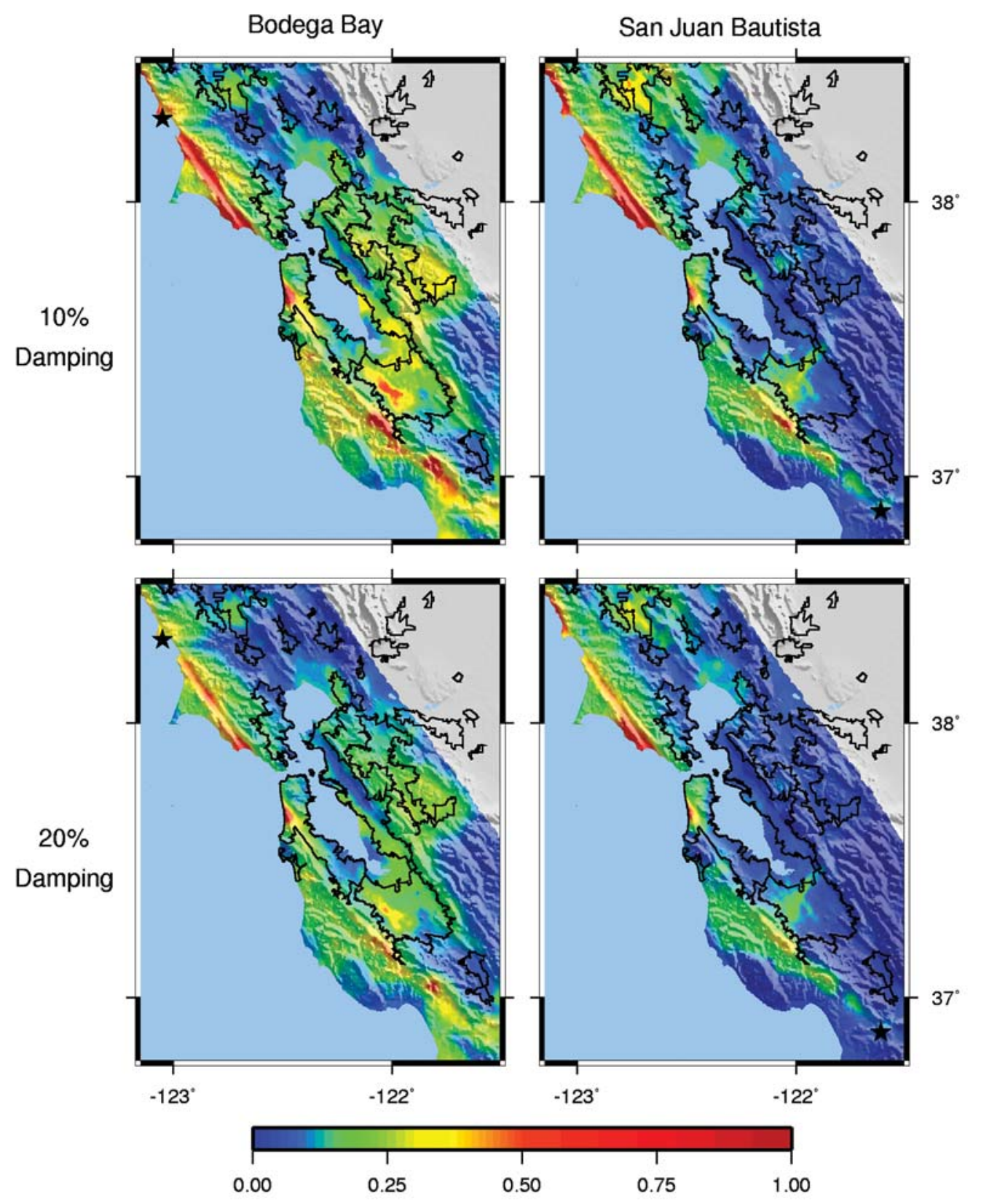

Figure 10. For linear isolators with a fundamental period of $2 \mathrm{sec}$, the predicted maximum isolator displacements are large on most of the San Francisco Bay Area in the two hypothetical earthquakes. Existing base-isolation systems may not be designed for isolator displacements this large. Also, we expect peak isolator displacements from nonlinear models to be larger than those predicted by these linear models. (Note coloring scheme is different than Fig. 11.)

by the building code. In this article, we consider the upper bound (sites on the San Andreas fault) and lower bound (sites with minimum spectral acceleration values in the area); the design spectrum at a specific site would lie between these bounds. The peak spectral accelerations at almost all periods from the three magnitude 7.8 earthquake ground motions exceed the upper bound for the 2006 IBC design spectrum. In the three earthquakes, the spectral accelerations exceed the
2006 IBC upper bound on approximately $1 \%$ or less of the urban area. In the Bodega Bay hypothetical earthquake, the spectral accelerations exceed the 2006 IBC lower bound on approximately $25 \%$ of the urban area, and in the other two magnitude 7.8 earthquakes, the ground motions exceed the lower bound on approximately $10 \%$ of the urban area.

Our response spectra from these three simulations should not be compared too closely with the design spectra. 


\section{Spectral Displacement [m] \\ Period is 3 seconds}

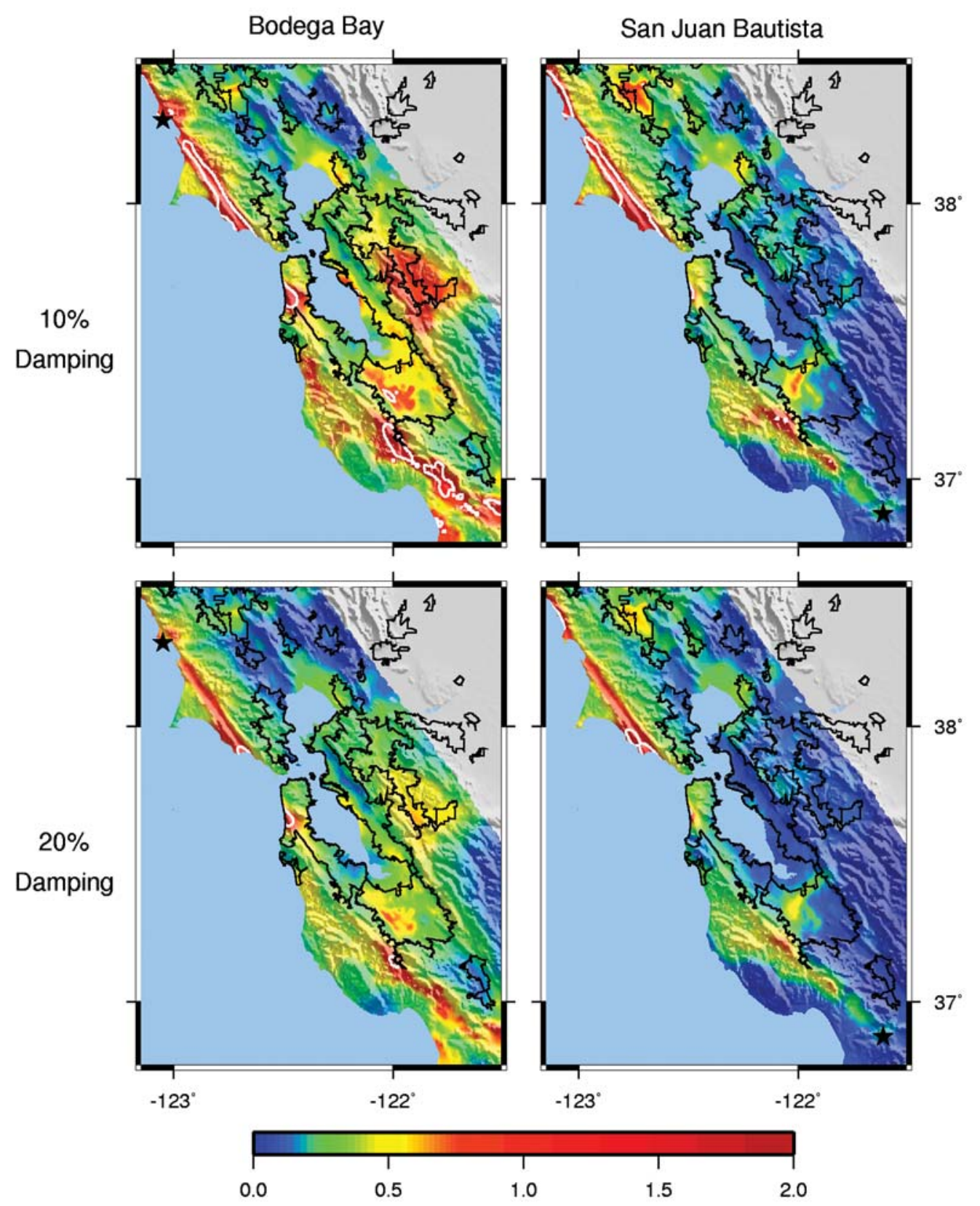

Figure 11. The magnitude 7.8 Bodega Bay and San Juan Bautista hypothetical earthquakes induce large isolator displacements in linear, 3 -sec isolators, and the 3-sec isolators give large displacements on a greater area than the 2-sec isolators. We expect peak isolator displacements from nonlinear models to be even larger (see text). Large damping reduces the peak isolator displacements. (Note coloring scheme is different than Fig. 10. The white contour is a peak isolator displacement of $1 \mathrm{~m}$, compared to the design maximum displacement of $0.5 \mathrm{~m}$ for two 3-sec systems in the San Francisco Bay Area.)

Our response spectra for the three magnitude 7.8 earthquakes are similar, with the Bodega Bay hypothetical earthquake producing higher spectral accelerations. The three earthquakes share the same assumed slip distribution, but the hypocenter and rupture direction are different for the simulations. A different slip distribution could give much lar- ger or smaller ground motions within the urban area. Furthermore, many Bay Area sites are on soils with shear-wave velocities of several hundred meters per second, and some important sites are on very soft soils with shear-wave velocities less than a hundred meters per second. At the resonant periods of these sites, the ground motions may be amplified 
Table 3

Percent of Urban Areas that Exceed Given Spectral Displacement (SD)

\begin{tabular}{clcccc}
\hline SD Cutoff & \multicolumn{1}{c}{ Simulation } & 2-sec Period 10\% Damping & 2-sec Period 20\% Damping & 3-sec Period 10\% Damping & 3-sec Period 20\% Damping \\
\hline \multirow{2}{*}{$0.4 \mathrm{~m}$} & M 7.8 Bodega Bay & 2.8 & 1.0 & 51 & 23 \\
& M 7.8 San Juan Bautista & 0.98 & 0.49 & 14 & 6.1 \\
$0.6 \mathrm{~m}$ & M 7.8 Bodega Bay & 0.70 & 0.34 & 19 & 4.8 \\
& M 7.8 San Juan Bautista & 0.28 & 0.031 & 3.9 & 0.92 \\
\multirow{2}{*}{$1.0 \mathrm{~m}$} & M 7.8 Bodega Bay & 0.031 & 0 & 1.7 & 0.58 \\
& M 7.8 San Juan Bautista & 0 & 0 & 0.24 & 0.031 \\
\hline
\end{tabular}

Linear spectral displacement is expected to be a conservative estimate of base-isolated building response. In these magnitude 7.8 hypothetical earthquakes, the models with a 2-sec period show large displacements on a smaller area compared to the models with a 3-sec period. Higher damping levels reduce the area where we expect to see large displacements. We expect more sites would exceed these levels in large ground motions and on soft-soil sites.

five times that of sites with seismic velocities greater than our minimum permitted value of $700 \mathrm{~m} / \mathrm{sec}$.

\section{Conclusions}

The long-period buildings we study show simulated responses that approach and reach failure on a large area in magnitude 7.8 earthquake simulations. The steel MRF models' responses in the 1989 Loma Prieta scenario are considerably smaller than those of the large magnitude simulations. A long-period building that withstood the ground motions in the 1989 Loma Prieta earthquake may experience significant damage in an event like the 1906 San Francisco earthquake. For all steel MRF building models, the building responses in the 1989 Loma Prieta scenario exceed the life safety level on no more than $0.4 \%$ of the urban area, compared to $1 \%-54 \%$ for the magnitude 7.8 simulations. Additionally, the variability in the long-period building models' responses at a single site to the three magnitude 7.8 simulations implies a large range of possible building responses, depending on the rupture direction.

The design of the steel MRF building affects the likelihood of large response. For the same ground motion, the stiffer, higher strength design tends to have a smaller IDR than the more flexible, lower strength design. Changing the design from the weaker to the stronger decreases the area of simulated collapse by a factor of 3-6. Our modeling suggests that buildings with brittle welds are vulnerable to longperiod ground motions from large earthquakes on the San Andreas fault. Fixing brittle welds decreases the area of imulated collapse by a factor of 20-30 or increases the likelihood of no simulated collapses.

Our assumptions influence the results in the following ways. We assume the most damaging building orientation by choosing the resultant of the horizontal ground motions that maximizes peak-to-peak velocity. An existing building may not have this damaging orientation, and thus the response would be smaller. Since the ground-motion simulations limit the minimum shear-wave speed to $700 \mathrm{~m} / \mathrm{sec}$, the ground motions do not include the amplification asso- ciated with soft near-surface sediments and artificial fill. Consequently, the predictions of building response for these models in areas of soft sediments or poorly compacted fill may be considered lower bounds. We cannot comment on buildings designed specifically for soft-soil sites. Considering these opposing influences, we believe our estimates are reasonable.

In these ground motions, equivalent-linear models of base-isolated buildings show estimates of isolator displacements of $0.4-1 \mathrm{~m}$. Local site amplification and nonlinear isolator behavior-not included in the ground motion and building models, respectively-would tend to increase the predicted estimates of base-isolator displacements. Since important government buildings, hospitals, and communication centers must remain functional after a large earthquake, engineers should continue to consider large ground motions, like the ones used in the study, when designing isolation systems for these types of buildings.

The peak spectral accelerations from the three magnitude 7.8 earthquakes exceed the upper bound of the 2006 IBC design spectra. On 10\%-25\% of the urban area, the spectral accelerations from the simulations exceed the lower bound of the current design spectrum. We conclude that some ground motions from these earthquakes exceed the current design-spectra values. This conclusion is limited because we do not account for the uncertainties in generating the ground motions, and we do not compare the response spectrum at each site to the corresponding site-specific design spectrum. Future simulations that account for the variability in slip distribution, hypocenter location, etc., and make site-specific comparisons, can provide additional information on the adequacy of the design spectra and MCE level defined in the 2006 IBC.

Modern long-period buildings have not experienced ground motions as large as those predicted by simulations of earthquakes like the one in 1906. Large long-period ground motions are a direct consequence of large fault slips in a great earthquake, and these large fault slips are the products of plate tectonics. Although great earthquakes are unusual, they are inevitable. These simulations provide insight 

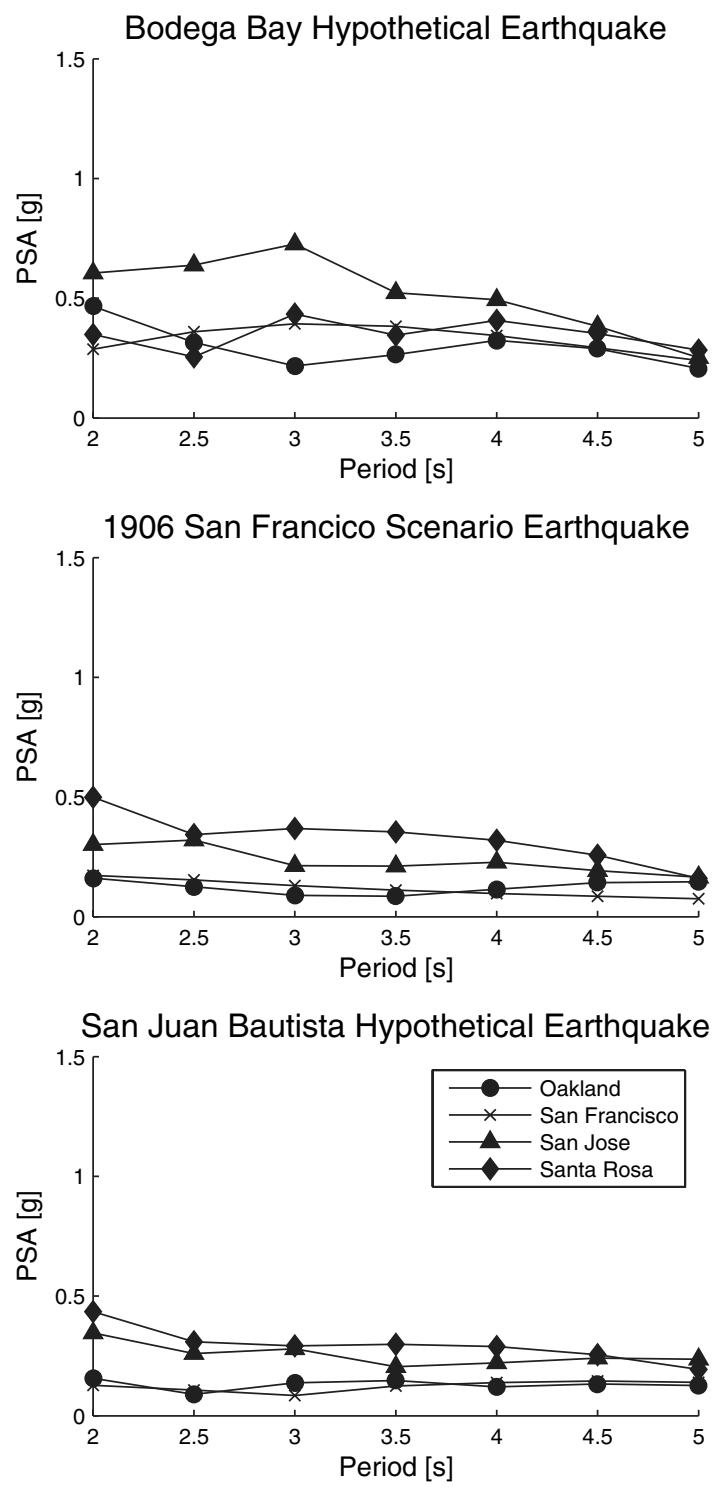

Figure 12. This figure shows standard response spectra at four sites in the San Francisco Bay Area for each magnitude 7.8 simulated earthquake. For each subdomain of the major cities we consider, we present the response spectra at a site with large pseudospectral acceleration (PSA) at $3 \mathrm{sec}$. Figure 1 locates the four sites with blue triangles. The energy content of our ground motions is limited to frequencies of $0.5 \mathrm{~Hz}$ and lower; the filter likely removes some energy at $2 \mathrm{sec}$, resulting in the flat response spectral values at that period.

into the possible response of modern long-period buildings in future great earthquakes.

\section{Acknowledgments}

The authors acknowledge the following individuals and groups for their contributions to this article. John Hall provided the MRF building models and help with interpreting the results. Keri Ryan provided generous guidance for interpreting the base-isolation results. The University of Southern California High Performance Computing Center provided computational resources for the simulations of MRF models. Luke Blair helped to generate
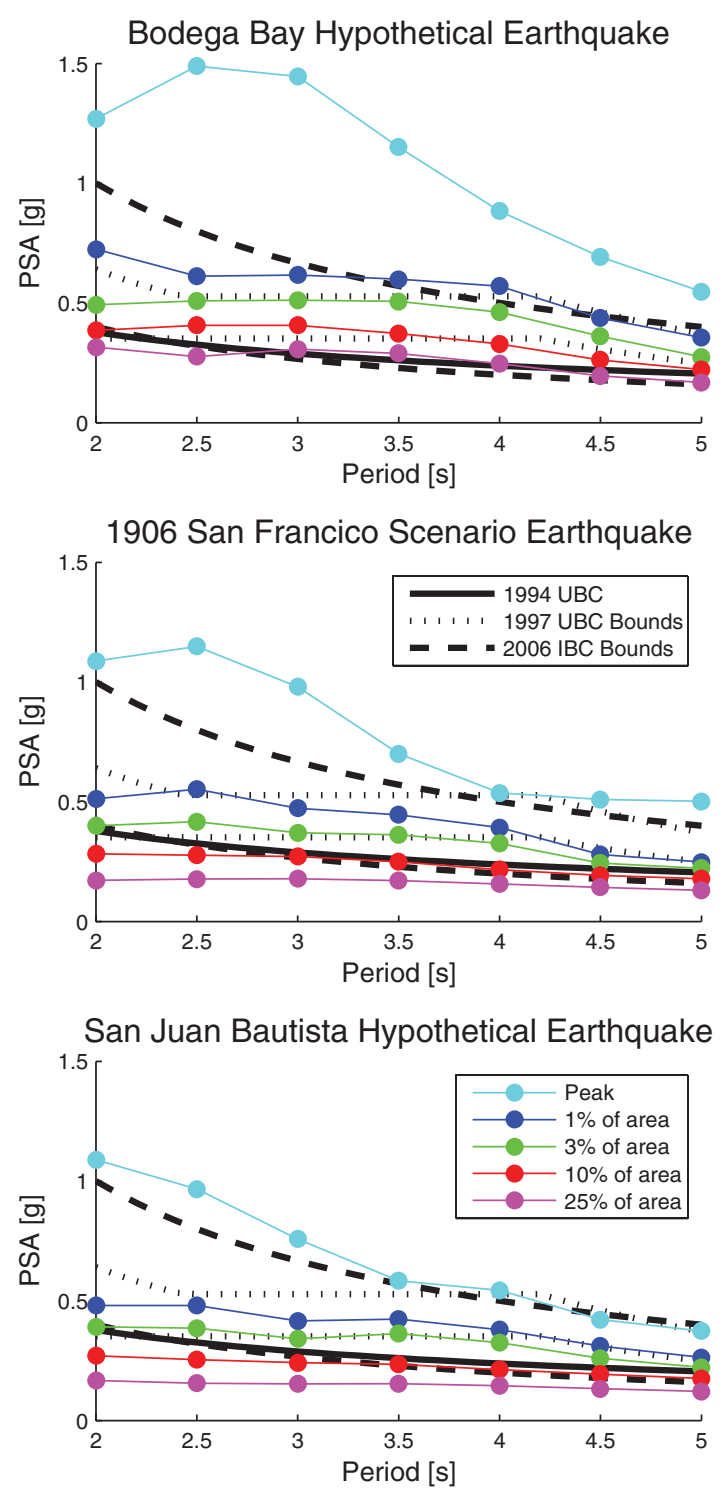

Figure 13. Because of the large number of sites in this study, we group the response spectra according to the urban area on which the ground motions exceed a certain pseudospectral acceleration (PSA). For example, in the 1906 San Francisco simulation, ground motions in $1 \%$ of the urban area exceed approximately $0.5 \mathrm{~g}$ for periods of 2-3 sec. We compare these response spectra for the simulated ground motions to the design spectra of the 1994 and 1997 UBC and of the 2006 IBC. The design spectra at a specific site in the San Francisco Bay Area lies between the upper and lower bounds of the 1997 UBC and 2006 IBC design spectra in this figure. The peak spectral accelerations in all three simulations exceed the upper bound of the 2006 IBC design spectra.

the urban outline. This research was supported by the Southern California Earthquake Center (SCEC). The SCEC is funded by National Science Foundation Cooperative Agreement EAR-0106924 and U.S. Geological Survey Cooperative Agreement 02HQAG0008. The SCEC contribution number for this article is 1135 . The Hartley Fellowship provided additional support. The authors thank the following reviewers for their thoughtful and helpful comments: Ruth Harris, Mehmet Celebi, one anonymous reviewer, and especially Nicolas Luco. 


\section{References}

Aagaard, B. T., T. M. Brocher, D. Dolenc, D. Dreger, R. W. Graves, S. Harmsen, S. Hartzell, S. Larsen, and M. L. Zoback (2008). Ground-motion modeling of the 1906 San Francisco earthquake, part I: Validation using the 1989 Loma Prieta earthquake 98, no. 2, 9891011.

Aagaard, B. T., T. M. Brocher, D. Dolenc, D. Dreger, R. W. Graves, S. Harmsen, S. Hartzell, S. Larsen, K. McCandless, S. Nilsson, N. A. Petersson, A. Rodgers, B. Sjögreen, and M. L. Zoback (2008) Ground-motion modeling of the 1906 San Francisco earthquake, part II: Ground-motion estimates for the 1906 earthquake and scenario events 98, no. 2, 1012-1046.

American Society of Civil Engineers (ASCE) (2000). FEMA Tech. Rept. 356, Prestandard and commentary for the seismic rehabilitation of buildings, Federal Emergency Management Agency, Washington, D.C.

Brocher, T., B. Aagaard, R. Simpson, and R. Jachens (2006). The new USGS 3D seismic velocity model for Northern California (abstract), Seism. Res. Lett. 77, no. 2, 271.

Building Research Institute (1996). Technical report, A survey report for building damages due to the 1995 Hyogo-Ken Nanbu earthquake, Japanese Ministry of Construction.

Chopra, A. K. (2001). Dynamics of Structures: Theory and Applications to Earthquake Engineering, Second Ed., Prentice Hall, Upper Saddle River, New Jersey.

Dobry, R., R. D. Borcherdt, C. B. Crouse, I. M. Idriss, W. B. Joyner, G. R. Martin, M. S. Power, E. E. Rinne, and R. B. Seed (2000).New site coefficients and site classification system used in recent building seismic code provisions, Earthq. Spectra 16, no. 1, 41-67.

EPS (2003). Example building applications: earthquake protection systems, available at www.earthquakeprotection.com/buildings.html (last accessed August 2007).

Gilani, A. S. (1997). FEMA Tech. Rept. 289/SAC-96-02. Connection test summaries, SAC Joint Venture, Federal Emergency Management Agency, Washington, D.C.

Gupta, A., and H. Krawinkler (2000). Behavior of ductile SMRFs at various seismic hazard levels, J. Struct. Eng. 126, no. 1, 98-107.

Hall, J. F. (1997). Tech. Rept. EERL 97-05, Seismic response of steel frame buildings to near-source ground motions, California Institute of Technology, Pasadena, California.

Hall, J. F. (1998). Seismic response of steel frame buildings to near-source ground motions, Earthq. Eng. Struct. Dyn. 27, 1445-1464.

Hall, J. F. (1999). Discussion: the role of damping in seismic isolation, Earthq. Eng. Struct. Dyn. 28, 1717-1720.

Hall, J. F., and V. R. M. Challa (1995). Beam-column modeling, J. Eng. Mech. 121, no. 12, 1284-1291.

Hamburger, R. O. (2003). Building code provisions for seismic resistance, in Earthquake Engineering Handbook, W.-F. Chen and C. Scawthorn (Editors), CRC Press, Boca Raton, Florida.

Hamburger, R. O., and N. A. Nazir (2003). Seismic design of steel structures, in Earthquake Engineering Handbook, W.-F. Chen and C. Scawthorn (Editors), CRC Press, Boca Raton, Florida.

Heaton, T. H., J. F. Hall, D. J. Wald, and M. W. Halling (1995). Response of high-rise and base-isolated buildings to a hypothetical $M_{\mathrm{w}} 7.0$ blind thrust earthquake, Science 267, 206-211.

Hough, S. E., P. A. Friberg, R. Busby, E. F. Field, K. H. Jacob, and R. D. Borcherdt (1990). Sediment-induced amplification and the collapse of the Nimitz freeway, Nature 344, 853-855.

International Code Council (2006). International Building Code 2006.

Jachens, R., R. Simpson, R. Graymer, C. Wentworth, and T. Brocher (2006). Three-dimensional geologic map of northern and central California: a basin model for supporting earthquake simulations and other predictive modeling (abstract), Seism. Res. Lett. 77, no. 2, 270.

Jangid, R. S., and J. M. Kelly (2001). Base isolation for near-fault motions, Earthq. Eng. Struct. Dyn. 30, 691-707.
Kelly, J. M. (1998). Seismic isolation of civil buildings in the USA, Prog. Struct. Eng. Mater. 1, no. 3, 279-285.

Kelly, J. M. (1999). The role of damping in seismic isolation, Earthq. Eng. Struct. Dyn. 28, 3-20.

Kelly, J. M. (2004). Seismic isolation, in Earthquake Engineering: From Engineering Seismology to Performance-Based Engineering, Y. Bozorgnia and V. V. Bertero (Editors), CRC Press, Boca Raton, Florida.

Krawinkler, H. (2000). FEMA Tech. Rept. 355C, State of the art report on systems performance of steel moment frames subject to earthquake ground shaking, SAC Joint Venture, Federal Emergency Management Agency, Washington, D.C.

Krishnan, S., C. Ji, D. Komatitsch, and J. Tromp (2006). Case studies of damage to tall steel moment-frame buildings in southern California during large San Andreas earthquakes, Bull. Seismol. Soc. Am. 96, no. $4 \mathrm{~A}, 1523-1537$.

Lawson, A. C. (1908). The California Earthquake of April 18, 1906: Report of the State Earthquake Investigation Commission (in two volumes and atlas), Carnegie Institution of Washington, Washington, D.C.

Lee, K., and D. A. Foutch (2006). Seismic evaluation of steel moment frame buildings designed using different R-values, J. Struct. Eng. 132, no. 9, 1461-1472.

Luco, N., and C. A. Cornell (2000). Effects of connection fractures on SMRF seismic drift demands, J. Struct. Eng. 126, no. 1, 127-136.

Roeder, C. (2000). FEMA Tech. Rept. 355D, State of the art report on connection performance, SAC Joint Venture, Federal Emergency Management Agency, Washington, D.C.

Ryan, K. L., and A. K. Chopra (2004a). Estimating the seismic displacement of friction pendulum isolators based on non-linear response history analysis, Earthq. Eng. Struct. Dyn. 33, 359-373.

Ryan, K. L., and A. K. Chopra (2004b). Estimation of seismic demands on isolators based on nonlinear analysis, J. Struct. Eng. 130, no. 3, 392402

Somerville, P., R. Graves, and C. Saikia (1995). FEMA Tech. Rept. SAC $95-$ 03, Characterization of ground motions during the Northridge earthquake of January 17, 1994, SAC Joint Venture, Federal Emergency Management Agency, Washington, D.C.

Soulé, F. (1907). The earthquake and fire and their effects on structural steel and steel-frame buildings, in The San Francisco Earthquake and Fire of April 18, 1906 and Their Effects on Structures and Structural Materials, U.S. Geol. Surv. Bull. 324, R Structural Materials, 1, Government Printing Office, Washington, D.C.

Structural Engineering Institute (SEI) (2006). ASCE Standard No. 7-05, Minimum design loads for buildings and other structures, American Society of Civil Engineers, Reston, Virginia.

Tobriner, S. (2006). An EERI reconnaissance report: damage to San Francisco in the 1906 earthquake: a centennial perspective, Earthq. Spectra 22, no. S2, S11-S41.

Walters, M. (2003). The seismic retrofit of the Oakland City Hall, in Proceedings of SMIP03 Seminar on Utilization of Strong-Motion Data, M. Huang (Editor), California Geological Survey, Oakland, California, 149-164.

California Institute of Technology

1200 E. California Blvd., MC 104-44

Pasadena, California 91125

(A.H.O., T.H.H.)

U.S. Geological Survey, MS 977

345 Middlefield Rd.

Menlo Park, California 94025

(B.T.A.)

Manuscript received 5 March 2007 